\title{
An unresponsive COVID-19 patient
}

\section{Pankaj Nepal ${ }^{1}$ (D) Prem Pradeep Batchala ${ }^{2} \cdot$ Swachchhanda Songmen ${ }^{1} \cdot$ Kalind Parashar $^{1} \cdot$ Joshua Sapire $^{1}$}

Received: 1 May 2020 / Accepted: 22 May 2020 / Published online: 28 May 2020

(C) American Society of Emergency Radiology 2020

\begin{abstract}
Neurological manifestations and complications are increasingly reported in coronavirus disease-19 (COVID-19) patients. Although pulmonary manifestations are more common, patients with severe disease may present with neurological symptoms such as in our case. We describe a case report of a 50-year-old male without previous known comorbidity who was found unresponsive due to COVID-19-related neurological complications. During this pandemic, an emergency radiologist should be well acquainted with various neurological manifestations of COVID-19. In this article, we will discuss the pathogenesis, imaging findings, and differentials of this disease.
\end{abstract}

Keywords SARS-CoV-2 · Coronavirus disease 2019 • Cytokine storm · MRI

\section{Introduction}

Coronavirus disease 2019 (COVID-19) is caused by severe acute respiratory syndrome coronavirus 2 (SARS-CoV-2). The virus primarily targets the respiratory tract in humans and presents with systemic and respiratory manifestations. However, since December 2019, multisystem involvement and complications including neurological have been reported with COVID-19 [1-3]. In a study of 214 subjects, Mao et al. reported neurological symptoms in $36.4 \%$ of the patients. Neurologic symptoms were more frequent with severe infection [4]. Presence of neuroimaging findings may be related to poor prognosis. The purpose of this article is to discuss

Pankaj Nepal

Pankaj-123@live.com

Prem Pradeep Batchala ppb2f@virginia.edu

Swachchhanda Songmen ssongmen@gmail.com

Kalind Parashar drkalind@gmail.com

Joshua Sapire

sappynyc@yahoo.com

1 St. Vincent's Medical Center, Bridgeport, CT, USA

2 University of Virginia Health System, Charlottesville, VA, USA spectrum of neuroimaging findings of COVID-19, correlating with various mechanisms of neurologic injury.

\section{Case report}

A 50-year-old male with no significant past medical history was brought in by emergency medical services (EMS) after he was found unresponsive at home. His wife, who found him unresponsive at 3:00 AM, stated he had abdominal pain, poor appetite, diarrhea, and vomiting for the last 2 days. She also reported high-grade fever in him the previous evening. Initially, EMS team was unable to protect his airway and his oxygen saturation was very low $(\mathrm{SPo} 2=33 \%)$. EMS intubated him on the way, and with the support of bag and mask, his oxygen saturation improved to $100 \%$.

In the ED, the patient was unresponsive to painful stimuli. Vital signs were as follows: axillary temperature $=101^{\circ} \mathrm{F}$, pulse rate $=97 / \mathrm{min}$, and blood pressure $=172 / 69 \mathrm{mmHg}$. On general exam, there was posturing with bilateral upper extremity extension on hyper-pronation. Neurological exam revealed normal pupillary, cough, and gag reflex. Initial laboratory workup showed normal total leukocyte count of $6.7 \times 10^{3}$ / mcL with lymphopenia and monocytosis. BUN was $40 \mathrm{mg} /$ $\mathrm{dL}$ and creatinine $=2.04 \mathrm{mg} / \mathrm{dL}$ suggestive of acute renal injury. Blood glucose was elevated at $426 \mathrm{mg} / \mathrm{dL}$ with $\mathrm{HbA} 1 \mathrm{c}$ at $13 \%$. Liver function was mildly deranged with AST $=57 \mathrm{U} / \mathrm{L}$. There was elevated troponin $(67 \mathrm{ng} / \mathrm{L})$ and decreased serum calcium $(8.1 \mathrm{mg} / \mathrm{dL})$. There was no evidence of ketoacidosis. 
EKG showed no ischemic changes. Patient received intravenous hydration with normal saline, Tylenol, and 10 units of insulin.

Chest radiograph revealed extensive airspace opacities in both lungs (Fig. 1). Coalescent opacities were suggestive of acute respiratory distress syndrome (ARDS). Given the ongoing pandemic, he was tested for COVID-19. His throat swab was positive for SARS-CoV-2 with real-time reverse-transcription polymerase chain reaction (RT-PCR). The initial diagnosis was COVID-19-related acute hypoxic respiratory failure with possible anoxic brain injury. A non-contrast head CT did not reveal hemorrhage or ischemia (Fig. 2). Vessel imaging was not performed because initial suspicion was anoxic brain injury. There was no clinical suspicion of acute ischemic stroke warranting endovascular or thrombolytic therapy. However, a brain MRI performed 7 days after the admission revealed multiple punctate ( 2 to $3 \mathrm{~mm}$ ) foci of restricted diffusion in centrum semiovale and periventricular white matter (Fig. 3) suggestive of acute infarcts of embolic origin or due to vasculitis. Apparent diffusion coefficient (ADC) map did not reveal any abnormality suggesting pseudo-normalization, subacute nature of ischemic injury (Fig. 4). There was no evidence to suggest global hypoxic injury.

The patient was sedated and ventilated with appropriate settings. Empirical treatment was instituted with azithromycin, hydroxychloroquine, zinc sulfate, and ampicillin-sulbactam. Relevant serum markers which included Ddimer (15,000 units), ferritin $(2600 \mathrm{ng} / \mathrm{mL})$, and LDH (528 U/L) were deranged. High procalcitonin level (12 ng/ $\mathrm{mL}$ ), uptrending troponin, and progressive elevated creatinine

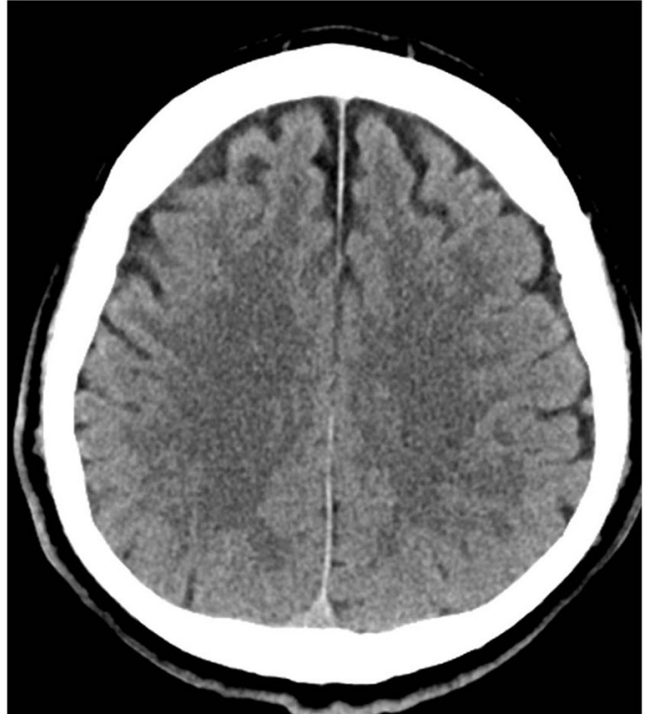

Fig. 2 Initial workup of the patient for altered mental status. CT head showing normal gray-white differentiation with no acute parenchymal hemorrhage or ischemic infarcts

of $6 \mathrm{mg} / \mathrm{dL}$ suggested worse prognosis. Neurological examination did not improve even after 14 days of admission, but brainstem reflexes were preserved.

\section{Discussion}

SARS-CoV-2 virus can inflict central nervous system (CNS) injury by direct (viral encephalitis) and indirect mechanisms.
Fig. 1 A 50-year-old man who was unresponsive with acute hypoxic respiratory failure. Chest radiograph showing extensive, bilateral airspace opacities throughout both lungs (yellow arrows) most consistent with ARDS due to viral pneumonia in the appropriate clinical setting. The patient is intubated (red arrow) with supportive other lines and tubes

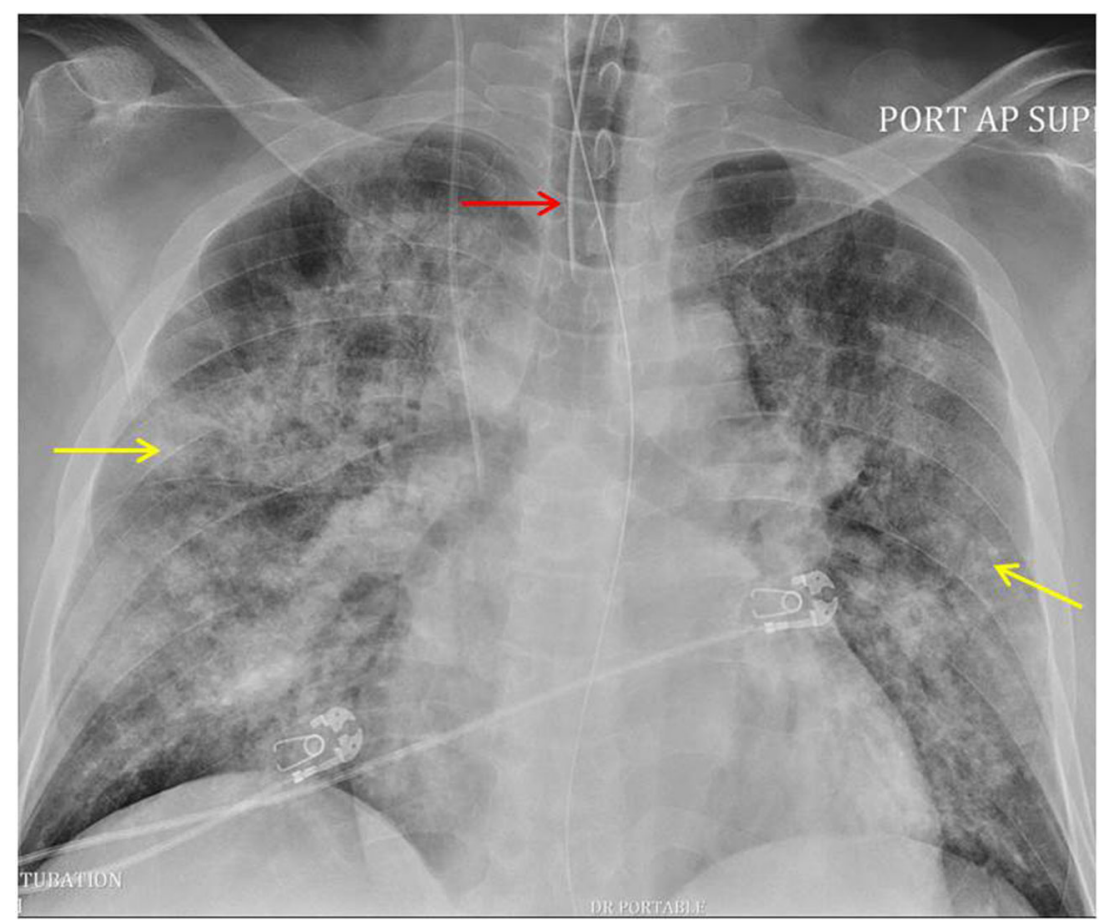




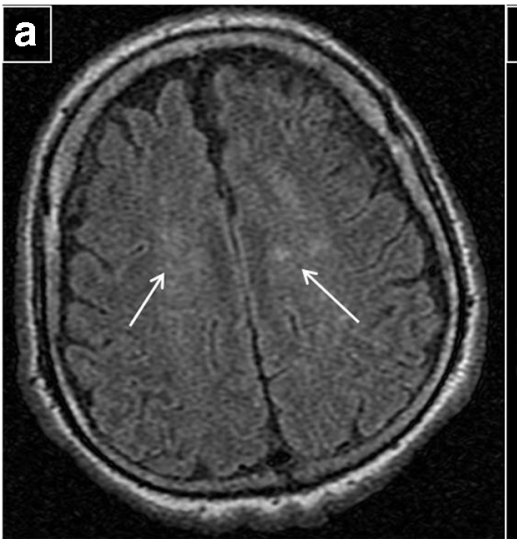

Fig. 3 Follow-up MRI examination of the patient to rule out anoxic brain injury. a Axial FLAIR sequence of the brain at the level of centrum semiovale showing bilateral, patchy, and confluent areas of hyperintense signals (white arrows). b, c Axial diffusion-weighted

SARS-CoV-2 binds to angiotensin-converting enzyme 2 (ACE-2) receptor for cell entry and reportedly with a higher affinity than SARS-CoV. The neurotropic properties of the virus are explained by the expression of the ACE-2 receptor by neurons and endothelial cells [4]. The virus gains entry to the central nervous system (CNS) via the bloodstream, via olfactory bulb in the roof of the nasal cavity or retrograde from the lungs via vagus nerve. Indirect mechanisms of CNS damage include hypoxic injury (from respiratory failure), immune-mediated injury (through interleukins and cytokines), and endothelial or blood-brain barrier injury (mediated through ACE-2 receptor). SARS-CoV can infect the brain stem [5], and it is plausible that SARS-CoV-2 has similar capabilities. Altered mentation and respiratory depression exhibited by several of the COVID-19 patients could be a result

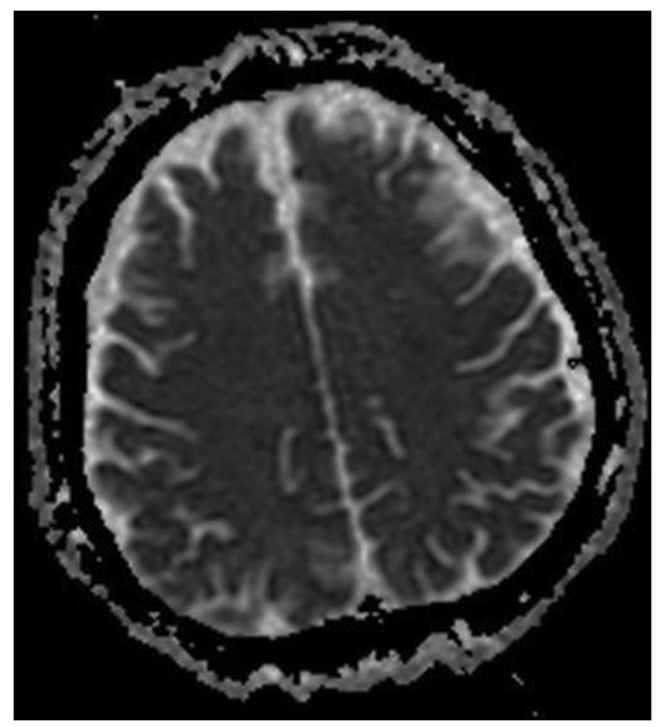

Fig. 4 Corresponding apparent diffusion coefficient (ADC) map did not reveal any abnormality suggesting pseudo-normalization of reticular activating system and cardiorespiratory center involvement in the brainstem.

The reported neurological manifestations of COVID-19 can be broadly classified into CNS or peripheral nervous system (PNS) involvement. Neurological manifestations are particularly common in patients with lymphopenia (immunosuppression), severe systemic infection, and elevated D-dimer [4]. CNS manifestations include headache, confusion, altered mental status, and seizures. PNS manifestations include neuralgia, altered taste and smell, and loss of vision [4]. Loss of smell (anosmia) is a common feature of many upper respiratory infections due to nasal congestion. However, in SARSCoV-2 infection, anosmia has also been reported in the absence of nasal congestion [6]. Loss of taste and smell reportedly appear early during the clinical course with SARS-CoV2 infection compared to SARS-CoV infection [6].

The current literature is limited regarding neuroimaging findings of COVID-19. In one study, 8 out of 13 intensive care patients with neurological findings had leptomeningeal enhancement as most common finding on MRI [7]. Another recent study by Kandemirli et al. reported cortical signal abnormalities on FLAIR images as the most common finding (37\%), associated with diffusion restriction and blooming artifact similar to findings seen with infectious/autoimmune encephalitis, seizure, hypoglycemia, and hypoxia [8]. Multiple mechanisms can lead to acute cerebrovascular events in COVID-19 patients. Neuroimaging has revealed hemorrhagic as well as ischemic strokes. Both large vessel- and small vessel-related acute infarcts have been reported [9-11]. Direct endothelial injury from the viral infection or activation of coagulation pathways can lead to formation of microthrombi and vascular occlusion. Few cases of catheterdirected thrombolysis of abrupt thrombotic occlusion of major cerebral arteries such as M1 or M2 segments have been reported [9-11]. Alternatively, the "cytokine storm" which is an overproduction of cytokines such as tumor necrosis factor 
(TNF) and interleukins (IL-6, IL-1 beta) leads to blood-brain barrier injury and augments inflammation $[12,13]$. A case of acute necrotizing encephalopathy seen with influenza and other viruses related to intracranial cytokine storm has been reported involving bilateral thalami, medial temporal lobes, and subinsular cortex [14]. Thrombosis of carotid arteries, internal jugular vein, and intracranial venous sinuses are also seen.

Lacunar infarcts are small $(0.2$ to $15 \mathrm{~mm})$ non-cortical infarcts caused by occlusion of penetrating branches of large cerebral artery. The differentials of lacunar infarcts involving multiple vascular territories such as in our case are vague. Multiple embolic infarcts have been associated with central source, such as aortic arch or carotid atheroma, thrombus associated with atrial fibrillation, atrial myxoma, cardiomyopathy, infective endocarditis, and cardiac/carotid instrumentation [15]. Emboli may also develop with intravenous or intra-arterial drug abuse, sepsis, and malignancies. Other causes of microthrombi associated with vasculopathy may be due to vasculitis, connective tissue disorders, and infection [16].

Multiple confounding factors were associated with our patient such as uncontrolled diabetes, prolonged stay in intensive care, hypoxia, and multiple medications which may simulate or alter neuroimaging findings. Patients with uncontrolled diabetes are vulnerable to small vessel disease and white matter changes. It is well known that uncontrolled diabetes is a risk factor for COVID-19related complications, but there is no published data to estimate increased incidence of small vessel stroke in COVD-19 patients with diabetes. The punctate acute infarcts seen in our index patient are most consistent with involvement of penetrating small vessels. These vessels are likely occluded from microthrombi, but alternatively, the thrombi could be of embolic origin from the systemic circulation. No central source of emboli was detected in our patient. Multifocal lacunar infarcts in our patient demonstrated diffusion restriction with ADC pseudonormalization suggesting subacute phase, thus clinically determined contributory to the ongoing poor neurologic examination. The pattern of small bilateral infarcts in our patient approximated a watershed distribution, but there was absence of profound or sustained hypotension during hospitalization.

\section{Conclusion}

Neurological manifestations of COVID-19 disease are being increasingly reported. Patients with severe systemic disease may initially present with acute neurological symptoms; thus, it is imperative that an emergency radiologist must be well versed with diverse neurological manifestations of this disease.
Acknowledgments Our patient, the great source of learning.

\section{Compliance with ethical standards}

Conflict of interest The authors declare that they have no conflict of interest.

\section{References}

1. Desforges M, Le Coupanec A, Dubeau P (2020) Human coronaviruses and other respiratory viruses: underestimated opportunistic pathogens of the central nervous system? Viruses. 12:14

2. Bohmwald K, Galvez N, Ríos M, Kalergis AM (2018) Neurologic alterations due to respiratory virus infections. Front Cell Neurosci $12: 386$

3. Asadi-Pooya AA, Simani L (2020 Apr 11) Central nervous system manifestations of COVID-19: a systematic review. J Neurol Sci 413:116832

4. Mao L, Jin H, Wang M, Hu Y, Chen S, He Q, Chang J, Hong C, Zhou Y, Wang D, Miao X, Li Y, Hu B (2020 Apr 10) Neurologic manifestations of hospitalized patients with coronavirus disease 2019 in Wuhan, China. JAMA Neurol. https://doi.org/10.1001/ jamaneurol.2020.1127

5. Li YC, Bai WZ, Hashikawa T (2020 Feb 27) The neuroinvasive potential of SARS-CoV2 may play a role in the respiratory failure of COVID-19 patients. J Med Virol 92:552-555. https://doi.org/10. 1002/jmv. 25728

6. Pleasure SJ, Green AJ, Josephson SA (2020) The Spectrum of neurologic disease in the severe acute respiratory syndrome coronavirus 2 pandemic infection: neurologists move to the frontlines. JAMA Neurol. https://doi.org/10.1001/jamaneurol.2020.1065 [Epub ahead of print]

7. Helms J, Kremer S, Merdji H, Clere-Jehl R, Schenck M, Kummerlen C, Collange O, Boulay C, Fafi-Kremer S, Ohana M, Anheim M, Meziani F (2020) Neurologic features in severe SARSCoV-2 infection. N Engl J Med. https://doi.org/10.1056/ NEJMc2008597

8. Kandemirli SG, Dogan L, Sarikaya ZT, Kara S, Akinci C, Kaya D, Kaya Y, Yildirim D, Tuzuner F, Yildirim MS, Ozluk E, Gucyetmez B, Karaarslan E, Koyluoglu I, Demirel Kaya HS, Mammadov O, Kisa Ozdemir I, Afsar N, Citci Yalcinkaya B, Rasimoglu S, Guduk DE, Kedir Jima A, Ilksoz A, Ersoz V, Yonca Eren M, Celtik N, Arslan S, Korkmazer B, Dincer SS, Gulek E, Dikmen I, Yazici M, Unsal S, Ljama T, Demirel I, Ayyıldız A, Kesimci I, Bolsoy Deveci S, Tutuncu M, Kizilkilic O, Telci L, Zengin R, Dincer A, Akinci IO, Kocer N (2020 May) Brain MRI findings in patients in the intensive care unit with COVID-19 infection. Radiology. 8:201697. https:// doi.org/10.1148/radiol.2020201697

9. Wu Y, Xu X, Chen Z, Duan J, Hashimoto K, Yang L, Liu C, Yang C. Nervous system involvement after infection with COVID-19 and other coronaviruses. Brain Behav Immun. 2020. pii: S08891591(20)30357-3

10. Natoli S, Oliveira V, Calabresi P, Maia LF, Pisani A (2020 Apr 25) Does SARS-Cov-2 invade the brain? Translational lessons from animal models. Eur J Neurol. https://doi.org/10.1111/ene.14277. [Epub ahead of print] Review

11. Oxley TJ, Mocco J, Majidi S, Kellner CP, Shoirah H, Singh IP, De Leacy RA, Shigematsu T, Ladner TR, Yaeger KA, Skliut M, Weinberger J, Dangayach NS, Bederson JB, Tuhrim S, Fifi JT (2020) Large-vessel stroke as a presenting feature of covid-19 in the young. N Engl J Med 382:e60. https://doi.org/10.1056/ NEJMc2009787. [Epub ahead of print] 
12. José RJ, Williams AE, Chambers RC (2014) Proteinase-activated receptors in fibroproliferative lung disease. Thorax. 69:190-192

13. Meduri GU, Kohler G, Headley S, Tolley E, Stentz F, Postlethwaite A (1995) Inflammatory cytokines in the BAL of patients with ARDS. Persistent elevation over time predicts poor outcome. Chest. 108:1303-1314

14. Poyiadji N, Shahin G, Noujaim D, Stone M, Patel S, Griffith B (2020 Mar) COVID-19-associated acute hemorrhagic necrotizing encephalopathy: CT and MRI features. Radiology. 31:201187. https://doi.org/10.1148/radiol.2020201187
15. Chowdhury D, Wardlaw JM, Dennis MS Are multiple acute small subcortical infarctions caused by embolic mechanisms?, Journal of Neurology, Neurosurgery \& Psychiatry 2004;75:1416-1420

16. Cannistraro RJ, Badi M, Eidelman BH, Dickson DW, Middlebrooks EH, Meschia JF (2019) CNS small vessel disease: a clinical review. Neurology. 92:1146-1156

Publisher's note Springer Nature remains neutral with regard to jurisdictional claims in published maps and institutional affiliations. 